\title{
EI mal en la escatología de Juan Luis Ruiz de la Peña
}

\author{
Yelsin Oswaldo SeVILla \\ Universidad Teológica de América Central, San José, Costa Rica
}

Resumen: El Catecismo de la Iglesia Católica indica que "No hay un rasgo del mensaje cristiano que no sea en parte una respuesta a la cuestión del mal" ${ }^{\prime}$. Si es verdad que el conjunto de la fe cristiana constituye la respuesta a la cuestión del mal, entonces no podemos prescindir de la reflexión que se ha llevado a cabo desde la escatología. Pues en principio, el tema por antonomasia ante el mal, es la esperanza, una esperanza que se va forjando desde el acontecimiento de la encarnación hasta la resurrección de Jesucristo. El mismo Jesús no deja sin esperanza a la humanidad, ya que promete la vida eterna, una vida en comunión con Dios. La vida del ser humano no queda diluida en la muerte, sino que Jesús abre las puertas para que el futuro del hombre tenga sentido. Por eso, en este artículo abordamos el mal desde la clave escatológica, teniendo en cuenta que, para Ruiz de la Peña, la escatología no contiene ninguna futurología y tampoco es una futurología más entre otras. Además, indica que a las futurologías les incumbe ajustar cuentas con los futuros móviles inmanentes, intrahistóricos. En cambio "la escatología apunta al futuro absoluto, trascendente, que sobreviene a la historia desde el exterior, y por tanto llamado a constituirse en su definitividad en la meta historia"2.

Palabras clave: Mal, Progreso, Futuro, Esperanza, Muerte, Resurrección, Vida

Abstract: The Catechism of the Catholic Church indicates that «There is not a single aspect of the Christian message that is not in part an answer to the question of evil.» If it is true that the whole of the Christian faith

${ }^{1}$ Catecismo de la Iglesia Católica, Asociación de Editores del Catecismo, Madrid 1992, n. 309.

2 RUiz de la PeÑa, Juan Luis, "Futurologías seculares y escatología cristiana”, en Studium Ovetense 6-9 (1978-1979) 199. 
constitutes the answer to the question of evil, then we cannot abstain from the reflection carried out from eschatology. For, in principle, the theme par excellence in the face of evil is hope, a hope that is forged from the event of the incarnation to the resurrection of Jesus Christ. Jesus himself does not leave humanity without hope, since he promises eternal life, a life in communion with God. The life of the human being is not diluted in death, but Jesus opens the doors so that the future of man has meaning. Therefore, in this article we approach the topic of evil from the eschatological viewpoint, considering that, for Ruiz de la Peña, eschatology does not contain any futurology, and it is not just one more futurology, among others. Further, he argues that it is incumbent on futurologies to adjust their accounts to mobile, immanent, intrahistoric futures. On the other hand, «eschatology points to the absolute, transcendent future, which overlaps history from the outside, and therefore transforms itself definitively into the meta-history.»

Key words: Evil, Progress, Future, Hope, Death, Resurrection, Life.

\section{La significatividad de la esperanza cristiana ante la fe en el progreso (1 P 3, 15: Dar razón de la esperanza)}

En la obra La otra dimensión. Escatología cristiana, aparece el gran tema de la Teología Fundamental: "Si alguien os pide explicaciones de vuestra esperanza estad dispuestos a defenderla, pero con modestia y respeto, con buena conciencia" (1 P 3,15). Es una tarea actual, y Ruiz de la Peña constata que estamos en una época donde la esperanza parece menguar. La disposición del hombre para estar abiertos al más allá se va desvaneciendo poco a poco con la fe en el progreso. No importa el futuro que nos pueda esperar después de la muerte, lo cierto es que ya estamos viviendo una seguridad en nuestra realidad inmanente.

Nuestro autor denuncia la realidad hacia la cual nos ha llevado la cultura tecnocrática. En primer lugar, dicha cultura ha provocado una reducción o banalización del mal y se oscurece el hecho del mal moral. Así, el hombre aparece como el ser que se puede equivocar, pero no pecar. La consecuencia que provoca esta manera de concebir la realidad es que ya no hay espacio para un concepto ético de culpa, que queda suplantado por el concepto de error. Esta suplantación del concepto ético, provoca no solo la cancelación del mal estructural de la injusticia, sino también de 
las desigualdades. En cuanto al mal físico, la muerte que es el mal por excelencia, también queda reducida a simple accidente propio de la fase estacional en la que nos encontramos. Un accidente puede remediarse con compañías de seguros o adelantos terapéuticos y sobran los discursos ${ }^{3}$. El hombre ha avanzado mucho en las investigaciones científicas y cree que tiene en sus manos el poder de controlar la realidad.

De esta manera, el hombre se va forjando su propio destino, nada tiene que esperar de un Dios que crea con amor y da al hombre la capacidad para trabajar la tierra. Nuestro autor resume la realidad que vive la sociedad contemporánea del siguiente modo: "la técnica ha entronizado al hombre como señor de su destino y dueño de su futuro"4. Además, Ruiz de la Peña afirma que: "porque puede atajar este o aquel mal dicha sociedad alardea de poder abolir un día el mal. Mientras tanto, lo niega, lo ignora o lo devalúa drásticamente" ${ }^{5}$.

La cultura tecnocrática en múltiples ocasiones se ha manifestado como la que tiene el poder para la superación o eliminación de cualquier sufrimiento que provoque dolor, en virtud de esto ha logrado grandes avances. El Papa Benedicto XVI en la Carta encíclica Spe salvi, nos recuerda que en la lucha contra el dolor físico se ha logrado grandes progresos, sin embargo, a la par de estos avances ha aumentado el sufrimiento de los inocentes y también de las dolencias psíquicas. El Papa no rechaza la lucha que se lleva a cabo para la superación del dolor, pero invita a que el hombre sea consciente de que no está en sus manos el poder extirpar el dolor del mundo. La humanidad no puede desprenderse de su limitación porque ninguno de nosotros somos capaces de eliminar el mal. El Papa concluye que "esto solo podría hacerlo Dios: y solo un Dios que, haciéndose hombre, entrase personalmente en la historia y sufriese en ella"6.

Por otra parte, si es verdad que el hombre se erige como dueño de su futuro, eso quiere decir que la realidad que percibe es lo único que le puede dar seguridad, fuera de eso cualquier cosa puede carecer de importancia.

${ }^{3}$ Ruiz de la PeÑa, Teología de la creación, Sal Terrae, Santander ${ }^{6}$ 1988, 162.

${ }^{4}$ Ruiz de la PeÑa, Juan Luis, La otra dimensión. Escatología cristiana, Sal Terrae, Santander 1986, 20.

${ }^{5}$ Ruiz de la Peña, Teología de la creación, 162.

${ }^{6}$ Benedicto XVI, Encíclica "Spe Salvi”, n. 36 (Benedicto XVI, Spe Salvi, BAC, Madrid 2007). 
Pero frente a esta manera de pensar, Ruiz de la Peña indica que "la tecnología puede incrementar el tener del hombre, pero no su ser. Y aquello por lo que clama el hombre finito, tácita o reflejante, es por un ser más"7. De esta manera, el creyente debe ser capaz de presentar al ser humano que el presente no es lo único que hay, el futuro no carece de novedad, la vida no puede agotarse en lo pronosticable y lo que es más importante:"si el futuro tiene un sentido para el hombre, es por lo que puede ofrecer de nuevo".

Además, la plenitud de sentido no es algo que pueda ofrecer el desarrollo de la técnica, pues lo que puede dar es una felicidad del aquí y ahora. Ante esta situación, Ruiz de la Peña está convencido que la única manera de cómo el hombre puede dar razón de su esperanza, es haciéndola verificable en la historia, y mostrar de algún modo que "el presente carece de futuro, si el futuro no actúa en el presente"

Nuestro autor, en la obra La Pascua de la creación, que es una revisión de los principales temas de la escatología que ya había abordado en La otra dimensión, agrega algo que puede iluminar la presentación de la esperanza cristina:

Los creyentes estamos más obligados que los increyentes a dar razón de nuestra esperanza de forma pública y manifiesta; a nosotros más que a nadie toca reconciliar el presente con el porvenir, impedir que se confunda el ya con el todavía no, lo penúltimo con lo último ${ }^{10}$.

Respecto a la responsabilidad que tiene cada cristiano de dar razón de su esperanza, Ruiz de la Peña ofrece una serie de indicaciones. En primer lugar, el creyente está llamado a dar testimonio de su esperanza en el mundo que le toca vivir. De este modo debe configurarse como un agente activo y no pasivo de la esperanza cristiana. Si es verdad que el creyente vive el futuro como mediación de futuro absoluto, no puede dejarse arrastrar por la fe en el progreso. Su esperanza no puede estar arraigada en la confianza que le generan los propios recursos de la técnica, sino que debe estar basada y alimentada en la fidelidad divina ${ }^{11}$.

\footnotetext{
${ }^{7}$ RUIZ de la PeÑa, La otra dimensión, 21.

${ }^{8}$ Ibid.

${ }^{9}$ Ibid., 26.

${ }^{10}$ Ruiz de la PeÑa, La pascua de la creación. Escatología, BAC, Madrid 1996, 17.

${ }^{11}$ Ruiz de la PeÑa, La otra dimensión, 25-26.
} 
En segundo lugar, el creyente tiene que ejercitar su temple de "esperante", que no sea solo el de la expectación intramundana. Es así como su vida ha de estar orientada al futuro absoluto que posibilita el encuentro con Dios y abre las puertas de una esperanza cerrada. Nuestro autor afirma que: "Solo la esperanza responde a las expectativas últimas del hombre" 12 . De este modo quiere salvaguardar la importancia de un futuro absoluto, pues sin este, el futuro humano queda absorbido por el presente. Esto permite mostrar a otros que la esperanza cristiana lejos de acabar con las expectativas humanas, les da un sentido y las conduce hacia la dimensión de Dios que no permite que nuestras esperas se tornen absurdas y sinsentido.

Ruiz de la Peña, inspirado en estas ideas, define la escatología como lo que:

Versa sobre el futuro del hombre. Mas no sobre cualquier futuro, sino sobre el futuro absoluto, sobre lo último del hombre. Hablando con mayor precisión, la escatología es la reflexión creyente sobre el futuro de la promesa aguardado por la esperanza cristiana ${ }^{13}$.

La esperanza cristiana es significativa, tanto por lo que ofrece en el futuro como por lo que ya ha ofrecido Jesucristo ${ }^{14}$ con su vida-muerte y resurrección. Nuestro autor considera que Jesucristo no solo es el fundamento de nuestra esperanza sino también su contenido, pues en Él todas las promesas de Dios han tenido su sí y su amén ${ }^{15}$. Si Jesucristo es el fundamento de nuestra esperanza lo es porque en él se concretiza el amor y la fidelidad de Dios por la humanidad. Desde esta perspectiva se puede comprender que, aunque en el mundo exista sufrimiento y las consecuencias son terribles, eso no quiere decir que no haya ninguna esperanza. Al

${ }^{12}$ Ibid., 27.

14 "La escatología cristiana no nos habla, por tanto, de un futuro intramundano superable en principio por cualquier otro acontecimiento, sino del futuro absoluto que es Dios mismo. Jesús, como acontecimiento escatológico, abre el sentido de las ultimidades del mundo y del hombre. Lo que en él ha acontecido ya de modo aún velado, lo que desde su resurrección es realidad en él que es la cabeza, espera la manifestación plena en todo su cuerpo" (LAdARia, Luis F., "Escatología”, en Latourelle, René-Fisichella, Rino-PiÉNinot, Salvador (eds.), Diccionario de teología fundamental, San Pablo, Madrid 2010, 380).

15 RuIZ de la PEÑA, La otra dimensión, 30. 
contrario, se debe pregonar con fuerza que: "ha surgido la estrella de la esperanza, el ancla del corazón llega hasta el trono de Dios. No se desata el mal en el hombre, sino que vence la luz: el sufrimiento sin dejar de ser sufrimiento se convierte a pesar de todo en canto de alabanza"16.

La forma en la que Dios irrumpe en la historia y que se narra en el Nuevo Testamento no es mediante una palabra divina que la comunica a través de los profetas como lo hacía en el Antiguo Testamento, sino que es mediante la historia personal y singular de Jesús ${ }^{17}$. Además, la esperanza que tiene el creyente, a juicio de nuestro autor, "no es ahora expectación de una novedad sin precedentes, sino que tiende a acentuar lo que falta en ese proceso abierto en y por Cristo" ${ }^{18}$. Desde esta perspectiva la escatología evita la reducción del futuro a un presente atemporal, así como la reducción del futuro a un futuro intramundano.

La reducción de la escatología que suplanta el futuro absoluto por un futuro intramundano es la que está relacionada con la fe en el progreso $^{19}$. Según Ruiz de la Peña, Kant que es uno de los representantes de esta corriente, cree que el hombre avanza hacia un estado de perfección ${ }^{20}$ de tal manera que el progreso, no solo alcanza el avance de la técnica, arte o pensamiento, sino que también se da a nivel de la estructura moral de la humanidad. En definitiva, el progreso conduce hacia lo mejor y se considera como el más alto bien. Nuestro autor dirá que "a ese más alto bien Kant no vacila en darle un nombre religioso, el reino de Dios, aunque no se trate de la irrupción de un poder trascendente, sino del desarrollo autónomo de la naturaleza humana" 21 .

Los deslumbrantes avances tecnológicos han propiciado el surgimiento de totalitarismos desintegradores del más elemental humanismo

${ }^{16}$ Benedicto XVI, Spe Salvi, BAC, Madrid 2007, n. 37.

${ }^{17}$ RuIZ de la PeÑa, La pascua de la creación, 28.

18 Ruiz de la PeÑa, La otra dimensión, 24.

19 Robert Nisbet menciona cinco premisas básicas de la idea de progreso: 1) la fe en el valor del pasado; 2) la convicción de que la civilización occidental es noble y superior a las otras; 3 ) la aceptación del valor del crecimiento económico y los adelantos tecnológicos; 4) la fe en la razón y en el conocimiento científico y erudito que nace de esta; 5) la fe en la importancia intrínseca en el valor inefable de la vida en el universo (NISBET, Robert, Historia de la idea de progreso, Gedisa, Barcelona 1981, 438).

${ }^{20} \mathrm{KANT}$, Immanuel, Ensayos sobre la paz, el progreso y el ideal cosmopolita, Cátedra, Madrid 2005.

${ }^{21}$ RuIZ dE LA PEÑa, La otra dimensión, 34. 
y ofrecen una eventual voluntad de poder. Nuestro autor indica que "en estas condiciones, profetizar una continua marcha ascensional hasta el final feliz parece demasiado ingenuo, puesto que cierra los ojos a esa realidad, típicamente humana que es el mal moral, el uso pervertido de la libertad" 22 . Sin embargo, reconoce que la técnica es necesaria para el hombre, pero la técnica no es el tecnocratismo y concluye que "los excesos de este han degradado el presente y amenazan con despojarnos del futuro" 23 . En cambio, la esperanza cristiana es capaz de ofrecer una "visión integradora, tan universalista como personalista. Esta original e irrepetible coherencia asegura la superioridad de la escatología cristiana sobre las futurologías laicas" ${ }^{24}$. Además, la escatología cristiana nos indica cómo Jesucristo es nuestra esperanza ${ }^{25}$.

\section{La muerte, el mal por excelencia y la esperanza en la tradición bíblica del Antiguo Testamento}

En este apartado desarrollaremos el tema de la muerte que es considerado como el mal por excelencia. La muerte es uno de los temas que más angustia al hombre (GS 18). Sin embargo, a la par de esta angustia está la propuesta de la escatología cristiana que hunde sus raíces en una esperanza que viene y se vive desde Dios. Dios no abandona al ser humano; es un Dios de vivos y no de muertos. Además, entrega a su Hijo que desde el acontecimiento de la resurrección es la respuesta a la muerte y nos ofrece la esperanza de la vida eterna.

22 Ibid., 37.

${ }^{23}$ Ruiz de la PEÑA, Futurologías seculares y escatología cristiana, 195.

${ }^{24}$ Ibid.

${ }^{25}$ El profesor Juan Alfaro afirma: "porque Cristo es acontecimiento escatológico en sí mismo, lo es también para nosotros, nuestro mundo y nuestra historia. Nuestra esperanza se funda en su existencia total, en su venida al mundo, en su muerte y resurrección; es decir, en Dios que nos ha dado su propio Hijo, lo ha entregado a la muerte y lo ha resucitado por nosotros (Rm 8, 31-34; 4, 24-25; 5, 8-11). Dios es para nosotros el "Dios de la esperanza" (Rm 15,13); Cristo es nuestra esperanza (Col 1,27; 1 Tim 1,1). Esto quiere decir que nuestra esperanza es Dios en Cristo, la presencia y la obra de Dios en la humanidad" (Alfaro, Juan, Esperanza Cristiana y liberación del hombre, Herder, Barcelona 1975, 137). 


\subsection{La muerte el mal por excelencia}

Ruiz de la Peña, en su tesis doctoral El hombre y su muerte. Antropología teológica actual, prefiere circunscribir el tema de la muerte al ámbito de la antropología teológica más que a la escatología. Las razones por las cuales hace esta opción son obvias, pues en su tesis doctoral lo que hace en primera instancia es presentar una descripción de cómo se ha abordado el tema de la muerte desde la doctrina de la Iglesia y teólogos como: san Anselmo, santo Tomás de Aquino, Escoto, Rahner, etc. Mientras que también recoge las principales afirmaciones de filósofos como Max Scheler, Martín Heidegger, Jean Paul Sartre, Karl Jasper, Gabriel Marcel y otros teólogos protestantes. Con ello lo que busca nuestro autor es tratar de reivindicar el tema de la muerte para que no quede banalizado por ciertas posturas que tratan de ver la muerte como el final de todo; es decir, con la muerte acaba lo que es el hombre, sus aspiraciones e ilusiones o lo que es peor, aún no hay nada que esperar después de la muerte.

En la obra La otra dimensión. Escatología cristiana, retoma el tema de la muerte con sumo interés, ya que la fe en el progreso no solo trajo como consecuencia un reduccionismo de la escatología al futuro intramundano y contribuyó a la deshumanización del mundo, sino que también trajo como consecuencia la banalización de la muerte. De hecho, en esta obra Ruiz de la Peña destaca que Karl Marx no dio importancia al tema de la muerte, incluso la ignoró como problema, mientras que Ernst Bloch, por su parte, intenta esclarecer el problema con su tesis de la exterritoria$\operatorname{lidad}^{26}$. Este último no hizo más que reavivar el sofisma de Epicuro: "la muerte no tiene por qué preocupar al hombre, pues mientras este sea, ella no será, y cuando ella sea, aquel no será" ${ }^{27}$.

Cabe señalar que, en esta obra, nuestro autor no hace un análisis exhaustivo de cómo Marx y Bloch tratan el tema de la muerte, pero sí lo

${ }^{26}$ Bloch sintetiza en dos proposiciones su conclusión sobre la tesis de exterritorialidad: primero: el núcleo del existir es, en cuanto aún-no-devenido, definitivamente exterritorial al devenir y al transcurrir, por lo que nuestro núcleo no es asible. Segundo: el núcleo del existir, supuesto que devenga y devenga bien, es, precisamente en este lograrse, exterritorialidad respecto a la muerte, pues esta misma resulta eludida y matada junto con la insuficiencia procesual a la que pertenece (BLOCH, El principio esperanza, III, Aguilar, Madrid 1980, 286).

${ }^{27}$ RUIZ DE LA PEÑa, La otra dimensión, 39. 
hará en otra obra Muerte y marxismo humanista. Aproximación teológica (1978). En ella encontramos una cita que él considera como la única en la que Marx se dedica al problema de la muerte: "la muerte aparece como una dura victoria de la especie sobre el individuo y (parece) contradecir a la unidad de la especie; pero el individuo determinado es solo un ser genérico determinado y, como tal, mortal" 28 .

En cuanto al filósofo Bloch, Ruiz de la Peña aclara que la muerte aparece aquí no como la entendía la mitología trascendentalista que por lo menos tiende su mirada hacia arriba, sino que la muerte aparece anclada nada más al proceso de la vida humana ${ }^{29}$ y "no a los sujetos de los que el proceso parte y a cuya identificación se dirige" 30 .

A juicio de nuestro autor, la escatología intramundana no puede prometer una patria de la identidad mientras exista la absoluta contradicción que es la muerte. En cambio, la esperanza que ofrece el cristianismo tiene algo mucho más novedoso que ofrecer: la resurrección de Jesús que pone en evidencia, que la muerte ha sido vencida (1 Co 15,26). En el libro $L a$ Pascua de la creación, nuestro autor añade algo muy iluminador que tiene que ver con la misión de la escatología:

La esperanza cristiana puede y debe atreverse a suscitar en su entorno la sospecha y la añoranza de la trascendencia, atajando de este modo el mortal riesgo que para todo proyecto de futuro supone la absolutización de la inmanencia. Tiene que hacer valer ante las esperanzas laicas un axioma sistemáticamente preterido por ellas, esto es, que el hombre espera por naturaleza algo que trasciende su naturaleza ${ }^{31}$.

La muerte es uno de los temas que más angustia al ser humano, pues muchas veces entra en crisis cuando se pregunta: ¿qué pasa con él después de la muerte? Ya hemos visto que la esperanza intramundana es incapaz

${ }^{28}$ Ruiz de la Peña, Muerte y marxismo humanista. Antropología teológica actual, Sígueme, Salamanca 1978, 15.

${ }^{29}$ Bloch indica que "al tratar la imagen de la muerte: lo que en ella encontramos es una reflexión sobre la liberación del hombre y de su nuevo espacio existencial, y nada más fuera de ello. En lugar de la mirada hacia lo alto, surge aquí una mirada que penetra en el origen que se dirige hacia adelante en el proceso y en la identificación de los hombres como el origen para un final feliz" (BLOCH, El principio esperanza, 286).

${ }^{30}$ RUIZ de LA PEÑA, Muerte y marxismo humanista, 15.

31 Ruiz de la PeÑa, La pascua de la creación, 32. 
de dar respuesta. Por esta razón, la esperanza cristiana tiene que tomar con absoluta seriedad el tema, no puede ser indiferente e ignorarlo como problema como lo hizo Marx o degradar la muerte a la nada si el hombre no es nada como apuntaba Bloch ${ }^{32}$. Nuestro autor afirma que "una esperanza que no sobrepuje la angustia de la muerte es una muy pequeña esperanza" 33 . El hombre que espera por naturaleza, algo que trascienda su naturaleza, también debe ser consciente que la victoria solo se puede dar si es capaz de trascender la historia.

Si el tema de la muerte es tomado con seriedad por nuestro autor, lo es porque en definitiva el hombre no solo está interesado en conocer lo que sucede en su entorno vital y el sentido que tiene el mundo y la historia, sino que también le interesa la pregunta por el sentido de la vida, ya que se encuentra muy cuestionado por la muerte. Desde el ámbito bíblico, se sugiere que es necesario partir de la vida misma para poder comprender la actitud del hombre ante la muerte.

Así, en el Antiguo Testamento, aparecen algunas verdades que iluminan el tema de la vida y la muerte. En primer lugar, la vida tiene un valor positivo, pues no es entendida como un mero existir por existir, sino que la vida es más que la mera existencia. El hombre vive la vida sumido en la confianza de su Dios y la felicidad que le proporciona. También las posesiones materiales son entendidas como un don de Dios ${ }^{34}$.

En segundo lugar, para el israelita existe la fuerte convicción de que es Dios el que otorga, conduce y prolonga la vida. De este modo, la vida adquiere un sentido nuevo y distinto, pues según Ruiz de la Peña no proviene de una fatal sucesión de los ciclos naturales, sino más bien de una voluntad libre y dialógica de Dios para con el hombre. De acuerdo con esto, todo lo que tenga que ver con la prosperidad, salud y larga vida, es porque "todo esto lo promete Dios a quien escucha su palabra y observa sus mandatos, porque la relación Dios-hombre confiere una plenitud vital integradora de todos los aspectos de la vida humana" 35 .

Desde este sentido positivo de la vida que es entendida como la suma de los bienes, por estar muy unida a la comunión con Dios y su promesa,

\footnotetext{
${ }^{32}$ Ruiz de la PeÑa, Muerte y marxismo humanista, 70.

${ }^{33}$ RUIZ de la PeÑA, La otra dimensión, 39.

${ }^{34}$ Ibid., 70.

35 Ibid., 72.
} 
aparecerá también lo más negativo: la muerte. Ella es entendida no como la suma de los bienes sino como la suma de todas las desgracias. De las citas bíblicas de Gn 15, 15;25, 28; 35, 29; 49, 29.33, nuestro autor concluye, que la muerte es vista como una resolución natural de los elementos que constituyen al hombre o simplemente la ley universal de toda carne. Sin embargo, estos textos no pueden callar lo siguiente: "la muerte es el mal por excelencia" 36 .

La muerte entendida como "el mal por excelencia", no solo permite comprenderla como la suma de las desgracias que pueda padecer cualquier ser humano, sino que comporta algo mucho más serio. Si la vida era considerada como el lugar de la comunión con Dios, la muerte significaba la incomunicación, una situación de práctica de excomunión ${ }^{37}$. Ruiz de la Peña afirma que tanto la muerte como la vida en la mentalidad israelita, no se entienden como algo simplemente referido a lo físico y biológico, sino que vida-muerte son conceptos teológicos. De ahí, que la muerte aparece como la enemiga de Dios que es tenido como el autor de la vida, en cambio la muerte es el poder del mal.

Por otra parte, la muerte como concepto teológico comienza a aparecer cuando la relación de comunión del hombre con Dios se debilita. En todo caso, la muerte no es algo querido por Dios. De hecho, Ruiz de la Peña sostiene esta afirmación, haciendo uso del libro de la Sabiduría 1, 13-14: "Dios no hizo la muerte ni goza destruyendo a los vivientes. Todo lo creó para que subsistiera; las criaturas del mundo son saludables, no hay veneno en ellas de muerte". Por lo tanto, si Dios no quiere la muerte o la muerte es la enemiga de Dios, debemos buscar en otro lugar que no sea Dios el origen de la muerte. Tal origen se encuentra en Sabiduría 2, 24: "pero la muerte entró en el mundo por la envida del diablo y los de su partido pasarán por ella".

Por otra parte, la muerte que en sí misma representa la incomunicación con Dios, queda patentizada en lo que la mentalidad israelita conocía como el $\operatorname{scheol}^{\beta 8}$, es decir, el lugar de los muertos. Ruiz de la Peña, atribuye

${ }^{36}$ Ibid., 73.

${ }^{37}$ RuIZ dE LA PEÑA, La pascua de la creación, 60.

${ }^{38} \mathrm{El}$ Scheol es descrito como el lugar de los muertos, "el muerto baja al Scheol donde lleva una existencia vacía, como una sombra. Puede aparecerse por lo que se le considera como un lugar temeroso y peligroso. Con todo está separado del lugar de los vivientes, del 
al scheol un carácter teológico, ya que representa no solo una distancia de la morada de Dios, sino que es lugar sin retorno ${ }^{39}$. El scheol significa la morada de todos los muertos, es un destino común para todos los seres humanos, según nuestro autor, no es el ámbito de retribución de cierta categoría moral de los muertos. En el Salmo 88, el scheol es descrito como un lugar terrible, donde nadie quiere estar, pues es el lugar de los muertos y Dios no se acuerda de ellos. En Job es descrito con la imagen de abismo, en última instancia es el lugar de perdición. A pesar de que esta presentación pueda ser simplista y decepcionante, a juicio de nuestro autor, nos deja básicamente dos enseñanzas: la vida es algo precioso y es un don de Dios, en cambio la muerte es en sí misma un mal. Pero queda el interrogante: ¿cómo retribuye Dios el bien y el mal? ${ }^{40}$.

\subsection{La esperanza en la tradición bíblica y la tesis retribucionista}

En la obra La otra dimensión, Ruiz de la Peña tratará el tema de la tesis retribucionista y enfatiza la esperanza que hay detrás de todo lo que se puede pensar de la vida y de la muerte: la vida entendida como la comunicación con Dios y la muerte como la incomunicación. La muerte es un mal en sí misma, porque deshumaniza al hombre y lo priva del Don de Dios, nadie quiere vivir esta experiencia y más el hombre piadoso que fiel a las observancias de la ley, cree merecer no solo una vida distinta sino un destino diferente. Por eso, es lógico pensar que la tesis retribucionista girará en torno al premio de los buenos y castigo de los malos: riqueza-pobreza, salud-enfermedad, abundancia-miseria, alegría-dolor etc. todo esto es de carácter temporal.

Como vimos, la tesis retribucionista se encuentra en varios textos de la Sagrada Escritura. Ruiz de la Peña recoge en esta obra algunos textos tomados de los libros sapienciales y salmos. En Proverbios $(4,13 ; 7,2 ; 9$, 6 ), se pone en evidencia que Dios premia con vida y felicidad a aquel que presta atención a la sabiduría, por el contrario, el pecador no goza nada

lugar de la vida, echado a una zona donde la comunicación es imposible, zona que es de destrucción de vida precisamente por la carencia de relaciones" (AUER, Johann-RATZINGER, Joseph, Curso de teología dogmática. Ratzinger, escatología, la muerte y la vida eterna, Herder 1980, 84).

${ }^{39}$ RUIZ DE LA PEÑa, La otra dimensión 77.

${ }^{40}$ Ibid., 78. 
de esto: lo que le espera es una vida desdichada y llena de miserias, no tiene larga vida, ni prosperidad (Sal 128). El énfasis de nuestro autor está en la esperanza, porque desde la tesis retribucionista, "la fidelidad de Yahvé no puede aquí defraudar a los que esperan en él"41.

El principio de retribución entra en crisis cuando choca con la experiencia. En esta ocasión Ruiz de la Peña no solo coloca a Job y Eclesiastés como los que hacen una crítica devastadora al principio de retribución ${ }^{42}$, sino que menciona al profeta Jeremías que, desde su experiencia personal, pone en tela de juicio que esto deba ser así y hace una pregunta: ¿por qué tienen suerte los malos y son felices los traidores? (Jer 12,1). Para nuestro autor, también Job desde su experiencia personal no ve que se cumpla el principio: "los buenos son felices y los malos desgraciados" ${ }^{43}$. El mismo Job dirá "Soy el hazmerreír de mi vecino: el que llama a Dios y le responde; se burla: el justo, el honrado" (Job 12, 4); "Mientras tanto hay paz en las tiendas de los salteadores, y viven tranquilos los que desafían a Dios" (Job 12,6). Pero a pesar de la experiencia trágica del dolor que Job padece, siempre sigue manteniendo la fe en la justicia y bondad de Dios.

Sin embargo, a pesar de que Job critica el principio de retribución, esta vez Ruiz de la Peña destaca el libro del Eclesiastés. La propuesta de este libro arrasa hasta con la sabiduría misma, todo es vanidad de vanidad. La vanidad tal y como la plantea Eclesiastés "no es otra cosa sino la ausencia de valores, que convierte la vida en algo sin sentido" 44 . Pero a pesar de toda la crítica que pueda contener Job y Eclesiastés al principio de retribución, nuestro autor afirma que:

${ }^{41}$ Ibid., 82.

42 Auer y Ratzinger indican que Qohelet y Job hacen ver cada uno a su modo el fracaso de los reductos de seguridad de que hasta entonces se había disfrutado. Ambos libros desembocan en una crítica radical al esquema obras-consecuencias. En Qohelet la vida y la muerte del hombre no tienen lógica alguna visible ( $\mathrm{Ecl} 2,16 \mathrm{~s})$, todo esto lleva a un profundo escepticismo: todo es absurdo y vano. Pero a pesar de lo absurdo queda una resignación que se aferra a seguir viviendo y confiando en un sentido desconocido. En cuanto a Job, expresa de una manera más dramática todavía la disputa interna de las escuelas sapienciales y de la condena de la sabiduría clásica de Israel en el esquema acciones-consecuencias, la cima de la disputa está representada por la apelación a Dios como salvador contra el Dios que se quiere palpar en las absurdas destrucciones (Job 19, 22-25). Job espera en el Dios creído contra el Dios experimentado confiándose al desconocido (AUER-RATZINGER, Escatología, 88-89).

${ }^{43}$ RuIz de la PeÑa, La otra dimensión, 85.

${ }^{44}$ Ibid., 87. 
Job y Qohelet plantean a la conciencia religiosa de Israel la necesidad inaplazable de abrir su esperanza a una dimensión trascendente, so pena de condenar la existencia a un absurdo, o de hacer a Dios responsable de una justicia universal ${ }^{45}$.

De esta manera, se postula dar un paso más en la comprensión tanto de la vida como de la muerte. La dimensión trascendente comienza a gestarse en una visión positiva que nos muestran los tres Salmos, que Ruiz de la Peña les da el título de "místicos": 16, 49 y 73. En estos salmos, podemos encontrar un cambio de paradigma. Antes el scheol era la morada y destino común de todos los muertos, ahora aparece la esperanza puesta en Dios como ese que no abandonará la vida del ser humano en el scheol, sino que le enseñará el camino de la vida y lo hartará de gozo en su presencia (Sal 16, 10-11). Aunque este salmo ${ }^{46}$ presente esta nueva manera de ver las cosas nuestro autor aclara que no hay que buscar en él una distinción entre un más acá y un más allá, pues este lenguaje resultaría muy extraño al autor del salmo ${ }^{47}$.

En el salmo 49 se da un paso más en la reflexión. Se comienza a hacer la distinción entre el lugar de los justos y los malvados. Los malvados aparecen como un rebaño pastoreado por la muerte, y aunque gocen de felicidad por poseer prosperidad y dinero en la vida temporal, de nada les servirá pues su morada es el scheol. En cambio, el justo puede tener la esperanza de que Dios rescatará su vida de las garras del scheol. Ruiz de la Peña nota que en este salmo hay un avance ya que la muerte es la clave desde donde se puede comprender lo siguiente: "ahí es donde se revela la inanidad de la existencia pecadora y por consiguiente lo bien fundado de la experiencia del creyente" 48 .

En el salmo 73, el principio de retribución provoca una fuerte crisis de fe en el salmista y esto lleva a reflexionar profundamente sobre el tema. Aquí el énfasis sigue puesto en la comunión con Dios y permite distinguir

${ }^{45}$ Ibid., 88-89.

46 "Aunque aquí no se pensara todavía directamente en la fe en la superación de la muerte, sin embargo, se percibe que Yahvéh es, indudablemente más fuerte que el Sheol. El orante se sabe seguro en las manos de Dios, que es indestructible poder de la vida" (AUER-RATZINGER, escatología, 90).

${ }^{47}$ RuIZ de LA PEÑA, La otra dimensión, 90.

${ }^{4}$ Ibid., 92. 
que la prosperidad de la que suelen gozar los malvados no puede provenir de dicha comunión, pues todo lo que poseen es efímero. Por otra parte, la verdadera felicidad no se encuentra en la prosperidad que se pueda tener en esta vida, sino que la verdadera felicidad es aquella que parte de y en la comunión con Dios. De este modo, nuestro autor dirá que: "los tres salmos dan testimonio de una actitud nueva en la que la esperanza no claudica ni siquiera ante la muerte" 49 .

Sin embargo, hay que decir que ni Job, Eclesiastés, y los tres salmos místicos agotan la reflexión sobre la esperanza. Ruiz de la Peña también echa mano de algunos oráculos proféticos (Os 6, 1-3; Ez 37, 1-14; Is 2427). Su importancia es tal, que nuestro autor nos dice que estos oráculos "hablan de la potestad que tiene Dios sobre la muerte y el retorno de los muertos a la vida por su intervención" 50 .

Hay dos verbos que nuestro autor considera claves para la comprensión: el verbo "levantarse" que lo encontramos en Os 6,1-3 y el verbo "revivir" que está en Ez 37, 14 e Is 24-27. Sin embargo, Ruiz de la Peña aclarará que en Oseas la expresión "levantará a su pueblo" (Os 6,1), no se habla de "una resurrección de los individuos, sino del pueblo en cuanto tal. Es el reino del norte el que expresa su confianza en la proximidad de la hora de su liberación" ${ }^{1}$. En Ezequiel, Dios aparece como el que tiene el poder de hacer surgir la vida de entre un montón de huesos secos (Ez 37,1-14). En el oráculo de Oseas y Ezequiel se puede apreciar la gran confianza que existe en Dios: en primer lugar, es capaz de devolver la vida a un organismo muerto y, en segundo lugar, Él es el Señor de la vida que puede rescatar de la muerte ${ }^{52}$.

Por otro lado, en Isaías 26, 19 se puede encontrar un primer anuncio de una resurrección de los individuos: "revivirán tus muertos, tus cadáveres resurgirán, despertarán y darán gritos de júbilo los moradores del polvo; pues tu rocío es rocío luminoso, y el país de las sombras parirá". Sin embargo, el texto que se acerca más a una idea de resurrección escatológica, según Ruiz de la Peña es Isaías 52, 13: "mi siervo será levantado” y Is 53, 10-11: "verá descendencia, alargará sus días...verá la luz".
49 Ibid., 94.
${ }^{50}$ Ibid., 95.
51 Ibid.
${ }^{52}$ Ibid., 96. 
En todo caso los testimonios más fidedignos de la idea de la resurrección de los muertos son Daniel 12, 2 y Macabeos 7 y 12. Daniel 12, 2 indica que: "muchos de los que descansan en el polvo de la tierra se despertarán, unos para la vida eterna, otros para vergüenza y horror eternos" 53 . Según nuestro autor, tanto en Daniel como 2 Macabeos se puede encontrar una respuesta al misterio de la muerte, aunque sea de manera limitada: "Dios resucitará a quienes hayan muerto por el honor de su nombre" ${ }^{54}$, pues la lucha de Dios contra todo tipo de mal incluyendo la muerte, se ve manifestada en la persona de Jesucristo.

\section{Jesús es la esperanza ante la angustia de la muerte del hombre}

Hemos visto en el Antiguo Testamento, que la muerte siempre pone en crisis al hombre, ya que trata de encontrar una respuesta ante tal angustia. También la experiencia de la muerte pone en crisis la fe de los individuos, crisis que es superada desde la mirada puesta en Dios como su salvador. Dios es más fuerte que la muerte, y esa fuerza se ve manifestada mediante la intervención en la historia con su Hijo Jesucristo.

La vida de Jesús tiene un desarrollo bastante dinámico, su misión consiste en predicar la Buena Nueva del reino de Dios. La explicación de este Reino de Dios, ha sido estudiada desde dos puntos de vista: la escatología consecuente y la escatología realizada. La primera, consiste en presentar el Reino de Dios como una magnitud estrictamente futura, aquí Ruiz de la Peña, menciona la postura de M. Werner. Este teólogo afirma que la predicación de Jesús versa sobre la cercanía del reino de Dios, pero no está presente ${ }^{55}$. Contraria a la postura de Werner citará a Charles Harol

${ }^{53}$ Esta es la formulación más clara de la fe en la resurrección en todo el Antiguo Testamento. Se relaciona contra las persecuciones helenísticas contra los judíos en la que fueron cobrando forma algunos de los testimonios más grandiosos de la fe de Israel. Además, tanto en Daniel como en 2Macabeos, la relación de pensamientos y experiencias de ambas obras se ve especialmente clara en la descripción de los martirios en 2 Mac, que se podría resumir así: a la vista de la persecución del creyente se encuentra con la cuestión de si debe preferir la justicia de Yahveh o su vida, su bios. Se encuentra ante la alternativa de escoger entre el derecho y su bios. El esquema relacional de obras-frutos no ayuda nada aquí (Auer-RATZinger, Escatología, 93).

${ }^{54}$ RUIZ de LA PEÑA, La otra dimensión, 99.

${ }_{55}$ Ibid., 107. 
Dodd, teólogo protestante que se le conoce por promover la escatología realizada. Esta segunda postura sostiene que el reino de Dios está ya presente en la vida, muerte y resurrección de Cristo, pero es incompatible con cualquier tipo de espera para el futuro ${ }^{56}$.

Ruiz de la Peña, opta por una postura bastante equilibrada. Para él, tanto la escatología consecuente como la escatología realizada no se excluyen mutuamente, sino que se complementan. Hay dos afirmaciones que iluminan la reflexión de nuestro autor:1) el reino de Dios se hace presente en Jesús, 2) el reino de Dios se consumará en el futuro. En el evangelio de san Lucas encontramos lo que Jesús dice a los fariseos: "pero si por el dedo de Dios expulso yo los demonios, es que ha llegado a vosotros el Reino de Dios" (Lc 11, 20).

Nuestro autor afirma la presencia del reino de Dios en la vida de Jesús, apelando a la idea de que en Jesús se da el cumplimiento de la promesa: "Dios ha entrado en la historia, el poder del demonio se tambalea, la enfermedad y el pecado (signos de ese poder) retroceden" 57 . Sin embargo, aclara que, aunque en la persona de Jesús y sus obras se haga presente el Reino que es cumplimiento de las promesas, eso no quiere indicar que ya está consumado. Esto se realizará en el futuro ${ }^{58}$. Una de las afirmaciones más importantes que encontramos en nuestro autor y, que sirve para conciliar tanto la escatología consecuente como la escatología realizada es la siguiente:

A la teología del reino propia de Jesús pertenece la dimensión futura del mismo entrañada en el juicio, resurrección, premio y castigo; sin ella el carácter salvífico de la presencia actual del reino resulta difícilmente explicable y convincente ${ }^{59}$.

Ruiz de la Peña, para mostrar que en la predicación de Jesús se encuentra presente no solo una escatología realizada como afirmaba Dodd, sino también una escatología consecuente, se vale de las parábolas que se refieren a la vigilancia: "vosotros estad preparados, pues cuando menos lo penséis, llegará este hombre" (Lc 12,40); "velad que no sabéis cuándo va a

\footnotetext{
56 Ibid., 111.

${ }^{57}$ Ibid., 122-123.

58 Ibid., 123.

59 Ibid., 125.
} 
llegar el amo de la casa" (Mc 13,35). Nuestro autor afirma que "la insistencia sobre la vigilancia cobra así un matiz de escatología futurista difícilmente eliminable" ${ }^{60}$. Por otra parte, los testimonios citados prueban dos cosas: en primer lugar, el carácter de futuro del Reino de Dios predicado por Jesús está avalado por un buen número de textos. En segundo lugar, que con la sola crítica literaria no hay razones de peso para dudar de que Jesús haya hablado de un siglo futuro que consumará al siglo presente. Además, prueba de ello es que el mismo Jesús siempre invita a orar por la venida del reino y estar siempre preparados para cuando venga el Hijo del hombre ${ }^{61}$.

Por otra parte, no hay que olvidar que también existe una tensión entre el ya y el todavía no del Reino de Dios. Existen varias parábolas que muestran un carácter escatológico, especialmente aquellas que se conocen como: "las parábolas del crecimiento" (Mc 4). Pero, hay una parábola muy importante que muestra una escatología consecuente, esta es la parábola de la cizaña (Mt 13, 24-30). Ruiz de la Peña, afirma que en esta parábola también se habla de crecimiento y ve en ella que "el reino del mal tiene ya ahora su contrapartida en el reino de Dios, aunque la discriminación se difiera hasta la siega"62.

Hay que decir que, las parábolas que invitan a estar vigilantes y las parábolas de crecimiento muestran claramente la presencialidad y futuridad del reino de Dios. Sin embargo, ambos componentes de la escatología no son para nuestro autor cuadros separados, sino que forman un cuadro unitario, de hecho, nuestro autor dice que:

La ética de Jesús, en suma, manifiesta y confirma la estructura tensional de la realidad del reino: su presencia capacita para (empuja a) la decisión en el ahora salvífico de la predicación; mas la decisión se orienta, a través de la perseverante firmeza, a la plenitud futura ${ }^{63}$.

Jesús, con su presencia en la historia de la humanidad, se convierte en la esperanza no solo para un núcleo de personas que confían en Él como el salvador, sino para toda una comunidad que ha observado en él algo dife-
${ }^{60}$ Ibid., 127.
${ }^{61}$ Ibid., 130.
${ }^{62}$ Ibid., 133.
${ }^{63}$ Ibid., 134. 
rente, una novedad sin precedencia alguna ${ }^{64}$. De hecho, Ruiz de la Peña considera que la escatología presente en el Nuevo Testamento es una cristología. Esta afirmación tiene su razón de ser en el mismo núcleo de la esperanza. Por una parte, la esperanza en el Antiguo Testamento estaba centrada en la intervención de Yahvé y sus acciones. En el Nuevo Testamento Jesús con su predicación y sus acciones se convierte en la esperanza y auténtico Éschatos. En pocas palabras, Jesús es el Señor de la historia.

Por otra parte, hay que indicar que la escatología del Nuevo Testamento es una cristología, ya que implica mantener una articulación bimembre: "porque Cristo ha venido, la escatología neotestamentaria es presentista; porque ha de venir, es a la vez futurista" ${ }^{65}$. Para Ruiz de la Peña, mantener la tensión entre el ya y todavía no, es muy importante, pues no podemos decantarnos por ninguno de los polos y de hacerlo caeríamos en graves errores. En la obra La pascua de la creación, nuestro autor expone sus razones:

Declarar realizada la escatología es cerrar los ojos a las actuales indignidades de la existencia, dar el visto bueno a las formas plurales de inhumanismo hoy vigentes, convalidar indiscriminadamente conductas y valores que pugnan con lo que la Biblia entiende por reino de Dios. En el extremo opuesto, una escatología futurista ignorará la significatividad de Jesucristo, reabsorberá el Nuevo Testamento en el Antiguo y, sobre todo, no concederá salvación sino a un presunto último tramo de la historia, secuestrando el resto de la misma en un estado de compleción insanable. Para salvar el futuro se condena el presente: este no tiene esperanza propia; a lo sumo suministra materiales, los materiales para elaborar los contenidos de una esperanza ajena ${ }^{66}$.

Por tanto, una adecuada interpretación de la escatología permite sin ambages dar el justo sentido a la esperanza del cristiano, y descubrir la significatividad de la doctrina escatológica del Nuevo Testamento. Yahvé

${ }^{64}$ Juan Alfaro afirma que Jesucristo "en su aparición en la historia, en su existencia en el mundo, en su muerte y definitivamente en su resurrección, Cristo lleva en sí mismo la dimensión interna de lo último del Eskhaton. Su tiempo era un tiempo tenso hacia la plenitud supratemporal futura, hacia el encuentro inmediato con Dios" (AlFARo, Esperanza cristiana, 136).

${ }^{65}$ RuIZ de LA PEÑA, La otra dimensión, 140.

${ }^{66}$ RuIZ de la PeÑa, La pascua de la creación, 116. 
considerado como el éschaton del Antiguo Testamento, ha decidido intervenir en la historia humana y, mostrar todo su amor en la persona de Jesús. Así, "el éschaton se implanta con la encarnación, vida, muerte y resurrección de Jesucristo, y se desarrolla en un marco temporal de duración indeterminada, que puede ser llamado la última hora, los últimos días, el nuevo eón y se consumará con la parusía del Señor resucitado"67.

Jesucristo es la esperanza, no solo porque él hace presente el Reino a través de sus palabras y obras, sino porque con su vida, muerte y resurrección, abre las puertas para una esperanza futura, que consiste estar en comunión con Dios y en las manos de Dios. De esta manera, con la encarnación de Jesucristo no solo el tiempo y el espacio adquieren un nuevo sentido, sino que también la muerte considerada como el mal por excelencia será interpretada desde un ámbito diferente. La vida humana no queda desnuda ante el acontecimiento de la muerte, pues como dice Ruiz de la Peña, "la resurrección de Cristo promete nuestra resurrección y, con ella nuestra victoria sobre la muerte" 68 .

Por otro lado, nuestro autor cree que es necesario el reconocimiento de una doctrina de la Parusía en el Nuevo Testamento, ya que manifiesta una idea que es sumamente importante para la esperanza cristiana. Se trata del Señorío que compete a Cristo desde su resurrección. "El resucitado terminará por imponerse al mundo y a la muerte como lo que es: como Señor de ambos. Este imponerse es la venida en poder que llamamos parusía" ${ }^{\circ}$.

La parusía no solo tiene un carácter revelador, sino que también es portadora de novedad. En cuanto reveladora, la parusía alimenta la esperanza del advenimiento de Cristo y el cumplimiento definitivo. En cuanto a la novedad, permite comprender que "la parusía entraña necesariamente la resurrección de los cristianos; la revelación del triunfo de Cristo no puede menos de repercutir en sus miembros. Todo esto, según Ruiz de la Peña, pone en "evidencia que, a la postre, nuestro Éschaton es Cristo; que la esperanza cristiana aguarda no algo, sino a alguien"70. La novedad de la parusía puede constatarse en las siguientes palabras:

\footnotetext{
${ }^{67}$ Ibid., 118.

${ }^{68}$ RUIZ DE LA PEÑA, La otra dimensión, 165.

${ }^{69}$ Ibid., 166.

${ }^{70}$ Ibid., 173.
} 
En cuanto tal novedad, la parusía no es otra cosa sino la resurrección, el juicio y la nueva creación; es decir, la anulación de la distancia que media todavía entre Cristo y el mundo. Distancia que, evidentemente, no es espacio-temporal (cuantitativa), sino ontológica (cualitativa). La humanidad, el mundo, no son aun lo que llegarán a ser, según la promesa incluida en la resurrección de Cristo. La parusía, más que ser una venida de Cristo al mundo, es una ida del mundo y los hombres a la forma de existencia gloriosa de Cristo resucitado ${ }^{71}$.

Ruiz de la Peña, en la obra El último sentido, que es un ensayo y no una obra sistemática como tal, expone tres pilares básicos desde los cuales se debe sostener la esperanza cristiana:

1) La venida de Cristo. Proclamar la venida de Cristo en poder, la victoria definitiva sobre el mal, la injusticia, el dolor, la muerte, es combatir para que se imponga el bien, la justicia, la felicidad, la vida. Pero existe una condición que consiste en que el reino que se anuncia llegará si los anunciantes realizan las obras del reino.

2) La fe en la parusía. Quien confiesa su fe en la parusía está manifestando su esperanza en un mundo y una humanidad donde la justicia, la libertad y la vida no son promesas vacías ni verdades a medias, sino una gloriosa realidad que ya desde ahora es posible y que, por tanto, es posible construir.

3) La fe en Cristo resucitado. Cristo resucitado ha vencido la muerte y ha sido constituido Señor. Pero su resurrección no representa tan solo el final feliz de una peripecia personal estrictamente privada. El misterio de la pascua es el misterio escatológico, la salvación de Dios operando desde la entraña de la historia e imprimiendo en ella un dinamismo irrefrenable hacia su consumación ${ }^{72}$.

\section{La credibilidad de la resurrección de Jesús, posibilita la esperanza de una resurrección de los muertos}

San Pablo en la primera carta a los Corintios 15,14 , pone de manifiesto la importancia de la resurrección de Jesús: "y si no resucitó Cristo,

\footnotetext{
${ }^{71}$ Ibid., 174.

72 Ruiz de la Peña, J. L., El último sentido, Marova, Madrid 1980, 80-81.
} 
vacía es nuestra predicación, vacía también vuestra fe". La esperanza de una resurrección de los muertos tiene su fundamento en la resurrección de Jesús. Ruiz de la Peña afirma constantemente que la muerte de Cristo vence al pecado, vence también la potencia destructora de la muerte, pero todo esto tiene su razón de ser desde la resurrección ${ }^{73}$. Pues, en definitiva, la resurrección tiene un significado profundo que subyace en la propia vida: "es la recuperada existencia del hombre, del hombre entero que había sucumbido en la muerte enteramente" ${ }^{74}$.

Desde la resurrección de Jesús, se puede entender que la vocación del hombre no es ser para la muerte, sino para la vida. En el evangelio de san Juan 14, 6, encontramos que Jesús se presenta como el camino, la verdad y la vida. De este modo, la vida del hombre no termina por sucumbir en las garras de la muerte total, sino en la vida eterna que promete Jesús.

Pero existían algunos en la comunidad de Corinto que creían que no había resurrección de los muertos y rechazaban también la concepción corporal de la resurrección. Frente a estos errores, según nuestro autor, san Pablo deja claro su pensamiento: "la negación de la resurrección corporal desintegra los fundamentos mismos de la fe y acaba con la auténtica esperanza de la salvación que no puede ser más que una salvación encarnada y escatológica"75. San Pablo trata de mostrar la credibilidad de la resurrección apelando a su mismo testimonio y rememora el acontecimiento de la muerte, sepultura y resurrección de Jesús, así como las apariciones a sus discípulos.

Mostrar la credibilidad de la resurrección es de máxima importancia, porque aquí se juega el fundamento de la fe cristiana y la esperanza futura de la resurrección de los muertos que profesamos en el Credo. Por esto, san Pablo se preocupa por mostrar que, si no es posible la resurrección de los muertos, o mejor dicho si los muertos no resucitan lo mismo valdrá en el caso de Cristo: tampoco Él ha resucitado. Ruiz de la Peña afirma que

73 "La esperanza en la resurrección de los muertos se puede vivir, por un lado, como resistencia contra el olvido social de los muertos y la represión de la muerte y, por otro, como motivo de esperanza para los olvidados, los aplastados por el progreso, los oprimidos por una historia de vencedores, como una esperanza que nos hace solidarios de ellos y toma posición contra la voluntad de autoafirmación absoluta que predomina en nuestra sociedad" (KeHL, Medard, Escatología, Sígueme, Salamanca 1992, 47).

${ }^{74}$ RUIZ DE LA PEÑA, El hombre y su muerte, 372.

${ }^{75}$ RuIZ dE LA PEÑA, La otra dimensión, 189. 
san Pablo establece un nexo indisoluble entre el destino de Cristo y el de los cristianos, es decir, si Cristo no ha resucitado, no hay posibilidad para que esperemos algo más allá de la muerte, no hay ninguna puerta abierta hacia el futuro del hombre. En pocas palabras, "si en Cristo ese futuro no ha sido la resurrección, ello significa que no hay futuro en absoluto para nadie" 76 .

Pero, como Cristo resucitó hay futuro para el hombre. Nuestro autor interpreta que en 1Corintios 15, 30-32 san Pablo muestra la necesidad de la esperanza en la resurrección, porque sin ella nada tiene sentido, todo es efímero y solo queda el "comamos y bebamos que mañana moriremos", de esta manera sucumbiríamos a un presente carente de futuro. Pero desde la resurrección todo tiene sentido, pues Jesús se manifiesta como la plenitud de la vida, y la presencia definitiva de la salvación. Además, el hombre puede configurarse con Cristo. Luis Francisco Ladaria afirma que "la perfecta configuración con Cristo resucitado y la participación de su vida constituye precisamente la vida eterna, el cielo" "77.

Desde la resurrección de Jesús, tanto la vida como la muerte del hombre adquieren una gran significatividad. Dios ratifica una vez más su poder sobre el espacio, y el tiempo de la historia y cualquier manifestación de poder que atente contra la vida. Dios no se olvida de la humanidad, hace palpable su amor queriendo al hombre como hombre y, no solo para un tiempo definido. La comunicación dialógica, que Dios inició con el hombre desde el momento de la creación, tiene carácter de perpetuidad y no meramente temporal.

Aquel a quien Dios habla, sea en ira, sea en gracia, le habla para toda la eternidad. La resurrección verifica la eficaz seriedad del propósito creador, al prometer más allá de la muerte la reconstitución del sujeto de diálogo en todas las dimensiones de su ser y, por tanto, también en la corporeidad $^{78}$.

Ruiz de la Peña está convencido que la muerte es la crisis suprema del hombre y como tal, también esta crisis alcanza a Dios. Pero dicha crisis tiene su contrapartida en la resurrección de Jesús que a su vez representa

\footnotetext{
${ }^{76}$ Ibid., 190.

${ }^{77}$ Ladaria, "Escatología", 382.

78 RUIZ DE LA PEÑA, La otra dimensión, 206.
} 
el hecho más amoroso de Dios y, lo es, porque no solo es la respuesta de Dios al interrogante de la muerte humana sino porque se cumple en ella la promesa de perennidad. El amor de Dios es para siempre y no solo para un momento puntual de la historia. De aquí, que "la resurrección cumple esa promesa; en cuanto tal cumplimiento, resurrección es el amor que esmás-fuerte-que-la-muerte"79.

Por otra parte, la solidaridad que Jesucristo ha mostrado con la humanidad juega un papel importante. Jesucristo no es indiferente a las necesidades humanas, se bate contra el mal en una lucha hasta la muerte. La muerte en cruz y la resurrección se convierten en la esperanza contra toda desesperanza. Por esto, nuestro autor dice: "creer desde la experiencia del mal es creer desde la esperanza en una victoria sobre el mal. Formulado cristológicamente: creer desde la cruz es creer desde la esperanza en la resurrección" $" 80$. Por otra parte, afirma que creer desde la experiencia del mal es alinearse contra toda forma de crucifixión, de aquí que la fe y la esperanza juegan un papel preponderante por lo siguiente:

Esperar es operar en la dirección de lo operado. Si se alberga la convicción de que el mal será totalmente vencido mañana, ello significa que puede ir siendo vencido hoy. La esperanza en la victoria quiebra el fatalismo del mal como ananké, como destino irrebasable; esa esperanza está, pues, contra la pasividad resignada y postula, para ser coherente, la actitud militante. Una actividad que es apuesta por la solidaridad en el dolor, por la confianza en la victoria sobre el dolor; que incluye la fe en la resurrección y en la vida, inseparable por lo demás, de la fe en la creación ${ }^{81}$.

Además, Dios nos ama y nos resucita, porque ha resucitado a Cristo y Cristo ha muerto por amor a todos. Ruiz de la Peña resume el cristocentrismo de la resurrección del siguiente modo: resucitamos a) porque Cristo ha resucitado; b) a imagen de Cristo resucitado; c) como miembros del cuerpo resucitado de Cristo ${ }^{82}$.

Cuando nuestro autor habla de resucitar a imagen de Cristo resucitado, pone el énfasis en lo que es la nueva creación, es decir, será resuci-

\footnotetext{
${ }^{79}$ Ibid., 207.

${ }^{80}$ RuIZ DE LA PEÑA, Teología de la creación, 173.

${ }^{81}$ Ibid., 174.

82 RUIZ DE LA PEÑA, La otra dimensión, 208-209.
} 
tado el yo de la existencia terrestre, pero tal identidad solo es alcanzable como puro don y como pura nueva creación. Esto es así, porque la resurrección de Cristo marca la pauta para considerar que el destino del hombre no es la muerte eterna, pues Cristo es el hombre nuevo que nos muestra que no somos simples piezas de engranaje en una realidad creada, nuestro destino no es la muerte sino la vida eterna.

En la obra La pascua de la creación, Ruiz de la Peña agrega un apartado nuevo que no encontramos en la obra La otra dimensión: "Sobre la credibilidad de la resurrección". Aquí, trata de mostrar con más fuerza argumentativa, que es necesario presentar la resurrección como una reivindicación de la justicia y la libertad para todos, una libertad que incluye la liberación de todas las alienaciones. Solo será posible presentar una justicia para todos, si se rehabilita al hombre para la vida, y se cree plenamente que hay victoria sobre la muerte, de lo contrario no existirá una victoria sobre la injusticia. Por tanto, nuestro autor concluye que "un auténtico proceso de liberación ha de incluir, por consiguiente, la certidumbre de una victoria sobre la muerte" $"$.

\section{Jesús da sentido a la historia del mundo y del hombre}

Para Ruiz de la Peña, la creación del cosmos y del hombre comporta la acción amorosa de Dios. Así, "el hombre no pudo haber nacido al margen del mundo, sino en el mundo; la historia de este es prehistoria de aquel; esta unidad nativa liga a ambos inseparablemente en cualquiera de las etapas de su existencia" ${ }^{44}$. Esta inseparabilidad hombre-cosmos le lleva a plasmar la idea de que el pecado del hombre también contamina la tierra y, por tanto, es objeto de maldición divina. La solución que plantea para abordar correctamente el tema es la siguiente: "la doctrina de una nueva humanidad entraña la de una nueva creación" 85 .

Esta propuesta implica la idea de que la salvación no solo está dirigida al hombre como tal, sino que también se dirige a la tierra y, será beneficiada con las bendiciones divinas ${ }^{86}$. Nuestro autor estima que la tierra

\footnotetext{
${ }^{83}$ Ruiz de la PeÑa, La pascua de la creación 179.

${ }^{84}$ RUIZ DE LA PEÑA, La otra dimensión, 215.

85 Ibid., 216.

${ }^{86}$ Ibid., 217.
} 
no es tan solo el escenario indiferente e inmutable de la historia humana, pues ella ha participado de la gestión, nacimiento y desarrollo del hombre y, por ende, también participará así mismo en su consumación. Es decir, "la consumación escatológica de la historia importa una dimensión cosmológica, plasmada en la promesa de cielos y tierra nuevos" 87 .

En la obra Teología de la Creación, se puede encontrar más detallada la unidad entre creación y redención de Cristo:

La convicción básica del Nuevo Testamento, según la cual Cristo es el fin de la creación y no solo el principio avanza la promesa de una victoria definitiva e irrevocable sobre el mal en sus diversas manifestaciones: el mal físico de la limitación, la caducidad, el dolor y la muerte; el mal ético del pecado; el mal estructural de la injusticia social, de la insolidaridad interhumana. Si Cristo es el fin único de todo lo creado, todo es redimible y salvable ${ }^{88}$.

Desde esta postura, la creación no puede ser tratada como algo separado del hombre. Tanto el cosmos como el hombre adquieren su pleno sentido desde el acontecimiento de Cristo, de tal modo que la protología deviene escatología en germen. Es así, como nuestro autor considera que "la fe en la creación es optimista, porque en su lógica se incluye la esperanza en la consumación" 89 . La carta a los Romanos 8, 19-23 es de suma importancia para la comprensión de la consumación de la creación, pues también la creación fue sometida a la vanidad, no por ella misma sino por aquel que la sometió. Así, también aguarda la esperanza de ser liberada de la servidumbre de la corrupción, ya que solo de esta manera será capaz de participar en la gloria de los hijos de Dios. Nuestro autor concluye que "la redención del universo no consiste simplemente en la resurrección de los muertos; atañe al universo mismo, que será liberado de lo que hay en él actualmente de vanidad, esclavitud, corrupción"90.

Ruiz de la Peña resume su pensamiento respecto a la esperanza escatológica del siguiente modo:

La esperanza escatológica cristiana escoge un justo medio entre el espiritualismo dualista, para el cual el mundo es malo y debe ser destruido, y

\footnotetext{
${ }^{87}$ Ibid.

${ }^{88}$ RuIZ DE LA PeÑa, Teología de la creación, 84.

${ }^{89}$ Ibid., 85.

${ }^{90}$ RuIZ DE LA PEÑA, La otra dimensión, 218-219.
} 
el materialismo monista, que ve en el cosmos una fuente de progreso permanente e inmanente y piensa en una humanidad prometeica, capaz de llegar por sí misma al vértice de su consumación. Frente a la tesis espiritualista, el cristiano cree que el mundo y el progreso no están consagrados a la destrucción, sino a una última y definitiva promoción. Frente a la utopía del progreso indefinido, el cristiano afirma que la consumación supera las virtualidades inmanentes, es don de Dios. En base a esta trascendencia del éschaton, se siente autorizado a ejercer una constante función crítica de las realizaciones intramundanas, puesto que ninguna de ellas se identifica con el futuro que le promete su esperanza ${ }^{91}$.

La esperanza cristiana frente a todo tipo de inmanentismo y utopías falsas es creíble, porque Jesucristo es su fuente ${ }^{92}$. Él da sentido a todo, porque todas las cosas fueron creadas por él y para él. La esperanza cristiana no hunde sus raíces en la fe en el progreso, ni se sostiene sobre una sociedad que es ciega y apática al mal ajeno, sino que su raíz es fuerte, porque en última instancia el amor de Dios robustece cualquier tipo de esperanza. Además, el amor se encuentra manifestado en toda la vida de Jesús, su vida misma es amor puro para con la humanidad. Se compadece de todos aquellos que necesitan una mano amiga, y tanto es así, que Jesucristo no solo promete resucitarnos, sino que también nos ofrece una vida eterna ${ }^{93}$.

Ruiz de la Peña, al analizar en qué consiste la vida eterna, se da cuenta que, en los evangelios sinópticos, la vida eterna es sinónimo de la fase final del reino y significa siempre el futuro escatológico. Y, ejemplo

${ }^{91}$ Ibid., 225.

${ }_{92}$ Medard Kehl indica que la esperanza cristiana vive en resistencia contra determinados extravíos de la sociedad moderna y si se profesa con convicción puede ser la base para evitar cualquier tipo de extravíos y buscar nuevos caminos más humanos. Por otro lado, la fe nos muestra al Dios de la esperanza como resistencia contra la imagen del hombre carente de misterio, contra la reducción del ser humano a un mero ser de necesidades, y también como fundamento para que los hombres se preocupen por el sufrimiento absurdo de otros y puedan anhelar la salvación y la justicia para todos (KeHL, Escatología, 46-47).

93 "Ha sido Cristo, resucitado, el que ha ganado esta victoria para el hombre, liberándolo de la muerte con su propia muerte. Para todo hombre que reflexione, la fe, apoyada en sólidos argumentos, responde satisfactoriamente al interrogante angustioso sobre el destino futuro del hombre, y al mismo tiempo ofrece la posibilidad de una comunión con nuestros mismos queridos hermanos arrebatados por la muerte, dándonos la esperanza de que poseen ya en Dios la vida verdadera" (CONCILIO VATICANO II, Constitución dogmática sobre la Iglesia “Gaudium et spes”, n. 18 (Documentos del Vaticano II, BAC, Madrid 1965). 
de ello es la parábola del juicio final de san Mateo 25,31, donde según nuestro autor, la vida eterna coincide con el reino preparado desde la creación del mundo. Por otro lado, en el evangelio de san Juan, la vida eterna adquiere unos rasgos característicos: vida eterna significa creer en Cristo que es la fuente de la vida. Y el pasaje evangélico de san Juan 17, 3 nos muestra que la vida eterna consiste en conocer a Dios, el único Dios verdadero y a su enviado Jesucristo. Nuestro autor, también cita Juan 17, 26 y nota que aquí, Juan identifica la vida eterna con la plenitud del amor: yo les he dado a conocer tu nombre, para que el amor con que tú me has amado esté en ellos como yo estoy en ellos ${ }^{94}$.

En todo caso, Ruiz de la Peña afirma que: "Lo que se denomina reino de Dios, paraíso, visión de Dios, vida eterna, no es sino esto: ser con Cristo, en la forma de existencia definitiva. Allí donde está Cristo, allí está el reino" ${ }^{95}$. Con esto, se subraya un fuerte cristocentrismo, porque Cristo es nuestro Éschaton y en él se ve manifestada la esperanza. Además, el ser con Cristo ${ }^{96}$ tiene un profundo significado, pues además de significar la plena comunicación del don de la vida, también permite al hombre ser partícipe ("vidente") de la esencia divina esto es el ser de Dios, que se hace posible mediante la encarnación. Por otra parte, la comunicación plena solo se puede dar en una estructura auténticamente humana, de aquí, nuestro autor se permite denominar la realidad humana del Hijo como: "el único lugar del encuentro entre el hombre y Dios"97.

La humanidad de Jesús reviste gran importancia por varios motivos: a) porque nos permite establecer una relación con Dios, b) es decisiva para nuestra salvación, c) nos permite una permanente apertura de nues-

${ }^{94}$ RUIZ DE LA PEÑA, La otra dimensión, 235.

95 Ibid., 238.

${ }^{96}$ Ruiz de la Peña dice que: "la constitución Lumen Gentium ha aportado a la doctrina del magisterio sustanciales complementos. En el n. 48 aparece el dato "visión de Dios: en gloria... seremos semejantes a Dios porque lo veremos tal como es". Pero inmediatamente añade el de "ser con Cristo, reinar con Cristo glorioso, entrar con él a las bodas"; en el n. 49 se afirma que "los bienaventurados están íntimamente unidos con Cristo", el cual "vendrá para ser glorificado en sus santos y mostrarse admirable en todos los que creyeron" (n 48). Como se ve, el acento cristológico se recalca aquí con firmeza. Por otra parte, se hace patente la índole social de la vida eterna en las frecuentes alusiones a la Iglesia cual sujeto de la misma (ya desde el comienzo del n. 48: "la Iglesia... se consumará en gloria celeste" (Ibid., 242).

${ }^{97}$ Ibid., 245. 
tra finitud al Dios vivo de la vida eterna e infinita, d) y finalmente nos permite contemplar al Padre ${ }^{98}$.

De los cuatro motivos citados, nos interesa especialmente el tercero: nos permite una permanente apertura de nuestra finitud al Dios vivo de la vida eterna e infinita. Este punto siempre representa lo esencial del mensaje de Jesús, porque él siempre nos promete la vida eterna. Ahora bien, Ruiz de la Peña en el capítulo VIII de La otra dimensión, trata el tema de la muerte eterna y afirma que la muerte eterna y la vida eterna no pueden ser considerados como si el cristianismo fuese una suerte de doctrina que presenta dos caminos o dos fines paralelos. La fe cristiana tiene un único fin, que es la salvación, además, este es el objeto propio de la escatología ${ }^{99}$.

Por otra parte, considera que la concepción original que tiene Jesús acerca del reino de Dios frente a la de los profetas, es que siempre anuncia solo la salvación, no la salvación y la condenación. Para sostener esta idea, nuestro autor recoge dos afirmaciones de los evangelios. En primer lugar, cita a Lc 15,1ss.; 18, 9-14, pues aquí aparece uno de los deseos más importantes que tiene Dios para con la humanidad entera: "Dios no quiere la muerte del pecador, sino que se convierta y viva". Y la otra cita es la de Jn 3,17 , aquí Jesús es presentado como el salvador, y de inmediato presenta también su misión: "porque Dios no ha enviado a su Hijo al mundo para condenar al mundo, sino para que el mundo se salve por él".

Aunque Ruiz de la Peña es consciente que la doctrina de la muerte eterna no pertenece al anuncio de la Buena Nueva de Jesús porque solo es de salvación, no obstante, cabe hablar del tema de la muerte eterna como posibilidad. Para él, ya desde el Antiguo Testamento se insinúa el tema de la muerte eterna, sobre todo cuando se habla del scheol como la morada de los impíos. Por lo que se refiere al Nuevo Testamento, la idea de la muerte eterna adquiere una pluralidad de significados: en primer lugar, es presentada en términos negativos que consiste en la negación de la comunión con Dios, a esta pertenecen algunas expresiones como: perder la vida, ser echado o quedar fuera, no heredar el reino o simplemente no ver la vida. Según nuestro autor, la condenación es presentada "como consistente, ante todo, en la exclusión de aquel acceso inmediato a Dios o a Cristo en la que los hombres alcanzan la vida eterna" ${ }^{100}$.
98 Ibid.
${ }^{99}$ Ibid., 251.
100 Ibid., 255. 
En segundo lugar, la muerte eterna es presentada en términos positivos: gehena de fuego, gusano que no muere, llanto y crujir de dientes, etc. Estas expresiones revisten un lenguaje simbólico, pues lo que se quiere poner de relieve, es que "la privación eterna de Dios supone para el hombre el trágico fracaso de su vida y, por ende, el mayor de los sufrimientos" ${ }^{101}$. Estas dos maneras de presentar la muerte eterna: exclusión de la vida con Dios y el aspecto doloroso que entraña dicha exclusión, nuestro autor dirá que "ambas series no remiten a elementos distintos y complementarios de la perdición, sino al único estado de muerte eterna, considerado siempre globalmente" ${ }^{102}$.

Además, aclara que, si no se quiere vaciar de contenido los textos bíblicos acerca del infierno, entonces hay que buscar en el hombre la causa de su existencia. Para justificar esta propuesta Ruiz de la Peña se vale de las citas de Jn 3, 17 y 12,14. Aquí la muerte eterna brota de la opción humana, y el juicio de condenación es entendido como autojuicio, de aquí surge la idea de que no es necesario que Dios haya creado o querido el infierno, sino que basta que el hombre exista, y que opte voluntariamente por una vida sin Dios. Y concluye que: "Solo habrá infierno para quien haya querido de modo lúcido y reflejo edificar su vida al margen de Dios" ${ }^{\prime 103}$.

\section{Conclusiones}

Este artículo nos ha servido para darnos cuenta que la escatología cristiana se interesa por el futuro del hombre, pero no de cualquier futuro sino de un futuro que nos permite trascender hacia la presencia de Dios y nos permite concluir que:

1) La existencia del hombre se mueve en una gama de propuestas que ofrecen bienestar y felicidad. Además, la tecnología ha tenido tal éxito que el hombre puede vivir su vida de manera cómoda. Nuestro autor reconoce que la técnica en cuanto tal es necesaria, sin embargo, aunque ayude al hombre y haga alarde de que un día puede abolir el mal, no hace

\footnotetext{
${ }^{101}$ Ibid., 256.

102 Ibid., 257.

103 Ibid., 263.
} 
otra cosa más que operar bajo el presupuesto de reducir todo al presente con la amenaza de despojarnos del futuro. En todo caso, el modelo tecnocrático no puede dar cuenta del futuro absoluto del hombre y tampoco puede ofrecer una plenitud de sentido porque la felicidad que nos ofrece es pasajera. Además, abolir el mal del mundo por parte del modelo tecnocrático puede resultar hasta utópico, porque el mal va más allá del simple hecho de querer acabar con las limitaciones físicas o las enfermedades.

2) Todos los creyentes que vivimos en una sociedad de muchos avances técnicos, estamos obligados a dar razón de nuestra esperanza y vivir nuestra vida con un talante de esperantes, teniendo en cuenta que Jesucristo con su vida, pasión, muerte y resurrección se convierte en el fundamento y contenido de nuestra esperanza. La esperanza cristiana ofrece sentido al yo, a la humanidad y al mundo. Jesucristo con su predicación y combate contra el mal, devuelve a la humanidad las ganas de vivir con sentido y no sumidos en el dolor, la angustia o desesperación que provoca el mal. Jesucristo nos abre las puertas y nos ofrece un futuro absoluto, una vida eterna entregada en las manos de Dios, de un Dios que triunfa sobre el mal venciéndolo en la cruz y resucitando a su Hijo de entre los muertos.

3) La muerte considerada como el mal por excelencia porque es uno de los temas que más angustia al hombre, tiene su respuesta en Jesucristo. Para Ruiz de la Peña, la muerte ha de perder su potencia devastadora desde la resurrección de Jesús. Además, el ser para la muerte se retrotrae en Cristo a su original vocación de ser para la vida. De esta manera, el cristiano vive no la muerte-ruptura, no la muerte-término, sino la muerte de Cristo, es decir, la muerte-transformación, la muerte-paso de la forma de existencia caduca y efímera a la vida eterna.

4) Por último, mostrar la credibilidad de la resurrección de Jesucristo es de importancia capital, porque la resurrección ilumina la vida y el destino del hombre. Y hay que decir que la muerte y resurrección de Jesucristo es la que nos permite creer en una victoria sobre el mal, sobre la muerte. 